\title{
Sexualidade e conjugalidade A redefinição das relações de gênero na França contemporânea*
}

\author{
Michel Bozon**
}

\begin{abstract}
Resumo
Um laço novo se estabeleceu entre sexualidade e vida conjugal nas últimas décadas do século $\mathrm{XX}$. Tradicionalmente o direito à atividade sexual era adquirido com o estatuto de sujeito casado; hoje em dia, o intercâmbio sexual passou a ser o motor interno da conjugalidade. No entanto, esta inversão não gerou uma transformação completa das relações de gênero. A análise das mudanças dos comportamentos na França contemporânea mostra sem dúvida uma aproximação das trajetórias sexuais femininas $e$ masculinas, e o desenvolvimento dum valor de reciprocidade entre parceiros. Mas o exame mais preciso do confronto dos homens $e$ das mulheres nas várias etapas do intercâmbio sexual sugere a permanência de uma divergência de gênero: tanto a socialização adolescente como o curso da vida conjugal continuam sustentando interpretações muito assimétricas da sexualidade, nas quais o desejo feminino tem menos legitimidade do que o masculino.
\end{abstract}

Palavras-chave: Sexualidade, Vida Conjugal, Relações de Gênero, França.

\footnotetext{
* Publicado em Bloss, Thierry. (org.) La dialectique des rapports hommesfemmes. Paris, PUF, 2001, pp.239-259. O comitê editorial dos Cadernos Pagu agradece a autorização da editora para traduzir este artigo. [Tradução: Plínio Dentzien.]

*** Institut National d'Etudes Démographiques - INED. booz@ined.fr
} 
Sexualidade e conjugalidade

Sexuality and Conjugality:

the Redefinition of Gender Relations in Contemporary France

\begin{abstract}
The relation between sexuality and conjugality has been deeply redefined in the last decades of the $\mathrm{XX}^{\text {th }}$ century. Whereas sex was traditionally a right and an attribute of married people, sexual exchange has presently become the inner driving force in contemporary conjugality. Nevertheless, this reversal has not brought about radical shifts in gender relations. An analysis of trends in sexual behaviours in France doubtless shows the closing of the gap between male and female sexual trajectories and the rise of a value of reciprocity between partners. But a closer examination of the confronting of men and women at the various stages of sexual exchange suggests the permanence of a strong gender divergence: teen age socialization, as well as the very course of conjugal sex life continue fostering very assimetrical interpretations of sexuality, in which female desire is always less legitimate than the male one.
\end{abstract}

Key Words: Sexuality, Conjugality, Gender Relations, France. 
Michel Bozon

\section{Introdução}

As mudanças conjugais contemporâneas traduzem a passagem de uma definição institucional antiga do casamento para uma definição interna e amplamente subjetiva do casal. Essa evolução aconteceu a longo prazo, mas conheceu uma aceleração decisiva nas últimas décadas. $\mathrm{O}$ processo multisecular da entrada do afeto nas relações conjugais/ familiares ${ }^{1}$ fez surgir, por exemplo, o ideal e a prática do casamento por amor $^{2}$, que se tornaram dominantes no século XX: o casamento por amor implica, de um lado, que o casamento não depende mais das negociações entre famílias, mas da escolha pessoal dos cônjuges ${ }^{3}$, e, de outro, que a única razão da escolha é o sentimento amoroso. Nas últimas décadas, o ideal do casamento por amor se dissolveu progressivamente no de casal por amor, por causa do enfraquecimento do casamento institucional ${ }^{4}$, que entretanto não equivale a um desaparecimento nem a um declínio da aspiração à união. $\mathrm{O}$ que caracteriza a união contemporânea não é só essa referência ao sentimento amoroso, mas também a importância crescente que assumiram, ao lado de um domínio conjugal em relativa decadência, os domínios e interesses individuais dos que se unem ${ }^{5}$, e também o papel essencial que assume a sexualidade,

\footnotetext{
1 ÁRIES, P. L'enfant et la vie familiale sous l'Ancien Régime. Paris, Seuil, 1973; LuHMANN, N. L'amour comme passion. Paris, Aubier, 1990 [Primeira edição em alemão: 1982].

2 DE Singly, F. Fortune et infortune de la femme mariée. Paris, PUF, 1987.

3 Bozon, M. Le choix du conjoint. In: DE SINGLy, F. (dir.) Famille. L'état des savoirs. Paris, La Découverte, 1991, pp.22-33.

${ }^{4}$ Na França, o número de casamentos caiu muito desde o início da década de 1970. Parte crescente dos que vivem juntos não se casam. Além disso, o casamento se tornou mais tardio entre os que se casam: já viveram um período de cohabitação, e muitas vezes já têm filhos. Finalmente, a estabilidade da união não está mais garantida, pois o divórcio atinge mais de um casamento em cada três.

${ }^{5}$ DE SINGLY, F. Le soi, le couple et la famille. Paris, Nathan, 1996.
} 
Sexualidade e conjugalidade

primeiro, na constituição $e$, depois, na manutenção da relação conjugal. ${ }^{6} \mathrm{~A}$ relação de dependência que ligava a sexualidade ao casamento foi completamente invertida: da instituição matrimonial que dava direito à atividade sexual passou-se ao intercâmbio sexual como motor interno da conjugalidade. A sexualidade, que era ontem um dos atributos do papel social do indivíduo casado, tornou-se uma experiência interpessoal indispensável à existência da união.

Se um laço novo se estabeleceu entre sexualidade e vida conjugal, podemos perguntar-nos se ele corresponde a uma transformação radical das relações entre homens e mulheres como a muito utilizada expressão "revolução sexual" daria a entender. Em um domínio vizinho, o da divisão do trabalho doméstico, a adesão maciça e nova dos homens e das mulheres a uma norma de igualdade não obteve uma verdadeira "tradução" nas práticas. ${ }^{7}$ O lado prático da "revolução sexual" deve ser questionado. As modificações das condições de existência das mulheres nas últimas décadas, em particular o considerável desenvolvimento de uma contracepção eficaz e controlada por elas, a elevação maciça de seu nível de instrução e a progressiva generalização do trabalho assalariado entre as mulheres de 25 a 49 anos, aumentaram fortemente sua autonomia social em relação aos homens, mas nada garante que o estilo das relações entre os sexos, tal como se exprime por exemplo no intercâmbio sexual, tenha sofrido uma revolução.

${ }^{6}$ Bozon, M. La nouvelle place de la sexualité dans la constitution du couple. Sciences sociales et santé, 4, 1991, pp.69-88; Amour, désir, durée. Cycle de la sexualité conjugale et rapports entre hommes et femmes. In: BAJOS, BOzON, FERRAND, Giami et SPIRA. La sexualité aux temps du sida. PUF, Paris, 1998, pp.175-234.

7 KaufmanN, J.C. Sociologie du couple. Paris, PUF, 1993; BROUSSE, C. La répartition du travail domestique entre conjoints reste très largement spécialisée et inégale. In: FRANCE. Portrait social. Paris, Insee, 1999, pp.135-151. 
Michel Bozon

\section{Normas e práticas em movimento: as mudanças sexuais das últimas décadas}

Com pouco mais de vinte anos de intervalo, um inquérito realizado em $1970^{8}$ e outros nos anos $90^{9}$ permitem compreender a transformação dos comportamentos sexuais na França, no decorrer das duas décadas geralmente consideradas como um período de "liberação sexual", na seqüência do movimento de idéias e da revolta estudantil (e operária) de maio de $1968 .{ }^{10}$

\section{Parceiros sexuais: estabilidade nas diferenças entre homens e mulheres}

Certos comportamentos parecem extremamente semelhantes, a despeito do tempo que os separa. O número médio de parceiros sexuais (do sexo oposto) que os homens entrevistados declaram ter tido no curso de suas vidas é idêntico: 12 parceiras em ambos os casos. Ao contrário, esse número aumenta para as mulheres, passando de 1,8 em 1970 a 3,2 em 1992. ${ }^{11}$ Não houve, pois, uma progressão irresistível no número de parceiros. O fenômeno mais espetacular é a manutenção de uma grande diferença nos números declarados pelos homens e pelas mulheres, ao que voltaremos adiante. A importância do recurso

\footnotetext{
8 Trata-se do inquérito Simon, realizado em 1970 com 2625 pessoas de mais de 18 anos. Simon, P.; Gondonneau, J.; MirOnder, L.; Dourlen-Roullier, A. M. Rapport sur le comportement sexuel des Français, Paris, Julliard et Charron, 1972.

9 Trata-se principalmente do inquérito ACSF (Análise dos Comportamentos Sexuais na França) realizado em 1992 com 20055 pessoas e do inquérito ACSJ (Análise do Comportamento Sexual dos Jovens) realizado em 1994 com 6182 jovens de 15 a 18 anos. Ver SPIRA, A.; BAJOS, N. et groupe ACSF. Les comportements sexuels en France. Paris, La Documentation Française, 1993.

${ }^{10}$ BozOn, M., LERIDON, H. e RIANDEY, B. Les comportements sexuels en France: d'un Rapport à l'autre. Population et Sociétés, 276, 1993.

${ }^{11}$ Os números medianos de parceiros são muito menores que os números médios: 5 para os homens e 1 para as mulheres.
} 
Sexualidade e conjugalidade

à prostituição se reduziu com o passar das gerações, pois somente 5\% dos homens entre 20 e 29 anos entrevistados em 1992 declaram ter recorrido a ela nos últimos cinco anos contra $25 \%$ da mesma idade em 1970 (em algum momento de suas vidas).

Outro dado relativamente estável é a proporção de pessoas que tiveram relações com pessoas do mesmo sexo no curso de suas vidas: 5\% declararam ter tido relações homossexuais em 1970 e $4 \%$ em 1992. As cifras correspondentes às mulheres são de 2 a $3 \%$. Há provavelmente uma sub-estimação.

\section{O alongamento da vida sexual das mulheres}

A transformação mais importante nas condições de exercício da sexualidade no decorrer da segunda metade do século XX é sem dúvida o alongamento da vida sexual, mais marcado para as mulheres do que para os homens. ${ }^{12}$

Houve uma diminuição na idade das mulheres quanto à primeira relação: para as mulheres nascidas em meados da década de 1970 a iniciação sexual se deu em média três anos mais cedo do que para aquelas nascidas cinqüenta anos antes, e um ano mais cedo do que para aquelas nascidas vinte anos antes. Para os homens, a diminuição no curso do meio século não foi mais do que cerca de um ano, uma vez que o ponto de partida já era mais baixo. A diferença entre homens e mulheres, que era de 2,5 anos para as pessoas que iniciaram sua vida sexual por volta de 1950, não existia mais para as que a iniciavam por volta de 1995, quando a idade mediana ao tempo da iniciação tanto para homens como para mulheres se situava nos 17,5 anos. ${ }^{13} \mathrm{~A}$ iniciação muito tardia desapareceu. Enquanto que nas gerações nascidas entre 1922 e 1941 era preciso esperar 23 anos para que três quartos das jovens tivessem uma experiência sexual, esse

12 BozOn, M. L'entrée dans la sexualité adulte. Le premier rapport et ses suites. Population, 5, 1993, pp.1317-1352.

${ }^{13}$ Lagrange, H. e Lhomond, B. L'entrée dans la sexualité. Le comportement des jeunes dans le contexte du sida. Paris, La Découverte, 1997. 
número não é maior que 19,5 anos para as nascidas entre 1956 e 1973. Há igualmente um estreitamento da variação da idade na iniciação: enquanto nas gerações mais velhas a iniciação se fazia num período de 6 anos, ela se concentra hoje no intervalo de cerca de 3 anos. $\mathrm{O}$ deslizamento para idades menores permite que hoje o conjunto das mulheres tenha uma vida sexual prématrimonial, pré-conjugal, enquanto que nas décadas de 1950 e 1960 ela era ainda um apanágio dos homens. A diminuição verificada no recurso dos homens jovens à prostituição se explica por essa nova possibilidade de ter como parceiras mulheres de idade semelhante.

Além disso, nas décadas de 1970 e 1980 a vida sexual também se modificou em suas fases tardias, prolongando-se por mais tempo depois dos 50 anos. Essa mudança vale para os indivíduos de ambos os sexos, mas de maneira mais notável para as mulheres. ${ }^{14}$ Assim, em 1970, apenas 50\% das mulheres casadas de mais de 50 anos tinham tido uma relação sexual durante o ano, ao passo que esse é o caso para $80 \%$ das mulheres casadas (incluindo as cohabitantes) da mesma idade em 1992. A menopausa, construção social e psicológica elaborada a partir de uma realidade biológica, deixou de sinalizar o fim da vida sexual, como o fazia ainda para boa parte das mulheres na década de 1960.

Foi instaurado um novo calendário da vida sexual, comum aos homens $e$ às mulheres, mas foi para as mulheres que isso representou a maior mudança. Há pouco tempo ainda sua vida sexual se identificava com sua vida fecunda de mulher casada. Esse cordão umbilical foi cortado em diversos lugares. Houve desde logo um relaxamento do controle estrito que pesava sobre a sexualidade feminina juvenil, acelerado pelo surgimento de formas modernas de contracepção. Entre as mulheres que vivem sós ou com crianças, eventualmente depois de uma separação, o fato de

${ }^{14}$ Delbès, C. e GAYMU, J. L'automne de l'amour: la vie sexuelle après 50 ans. Population, 6, 1997, pp.1439-1484. 
Sexualidade e conjugalidade

ter uma vida sexual não inscrita no quadro de um casal tornou-se freqüente e aceito. Paradoxalmente, é o prolongamento da sexualidade das mulheres de idade mais avançada que encontra mais resistência.

\section{A ampliação do repertório entre os parceiros}

Desde a década de 1960 o repertório sexual dos indivíduos e dos casais se ampliou claramente. Assim, o sexo oral conheceu grande difusão: em 1992, três quartos dos homens e das mulheres declaravam ter experimentado o cunilingus e a felação, e a proporção aumenta para $90 \%$ entre os indivíduos de 25 a 34 anos. Em 1970 apenas $60 \%$ dos homens e $55 \%$ das mulheres tinham conhecido alguma dessas práticas ao longo de suas vidas. A prática mútua do sexo oral é hoje uma das manifestações mais comuns da reciprocidade no seio dos casais, enquanto há apenas algumas décadas a felação era considerada como uma especialidade das prostitutas. A prática do sexo anal é declarada com maior freqüência que há vinte anos, embora continue uma atividade rara: em 1992, 30\% dos homens e $24 \%$ das mulheres declaravam ter tido a experiência (contra 19\% e $14 \%$ respectivamente em 1970). Permanece uma grande diferença nas declarações relativas à masturbação. As mulheres declaram ter se masturbado no curso de suas vidas com muito menos freqüência do que os homens ( $42 \%$ contra $84 \%$ ), mas é muito mais do que em 1970 (19\% contra 73\%). Se a prática provavelmente aumentou, é possível que um contexto social mais tolerante tenha facilitado a declaração no período mais recente. Se a freqüência média das relações sexuais não aumentou quase nada da década de 1970 até os anos 90 (cerca de 8 relações no mês anterior à pesquisa), a duração das relações aumentou, provavelmente em razão de um prolongamento dos preliminares amorosos. 
Michel Bozon

\section{Novas atitudes das mulheres}

Avaliar a satisfação dos indivíduos em relação à vida sexual evidentemente não é fácil. Da década de 1970 à de 90, ainda que as perguntas não fossem idênticas, nota-se um ligeiro aumento da satisfação masculina (de $41 \%$ para $47 \%$ de muito satisfeitos), mas, sobretudo, uma espetacular progressão feminina (de 26\% para $51 \%$ ). Válida para todas as idades, a progressão é particularmente marcada entre as mulheres de mais de 50 anos (de 14\% para $42 \%)$. Esse crescimento da satisfação feminina é, sem dúvida, devido a uma atitude mais ativa e mais hedonista da parte delas nos relacionamentos amorosos. Tanto em 1970 como em 1992, foi feita uma pergunta sobre a importância atribuída ao orgasmo simultâneo nas relações sexuais. A adesão à norma do orgasmo simultâneo recuou bastante nesses vinte anos, em particular entre as mulheres jovens. Essa aspiração menos forte ao prazer simultâneo traduz o recuo, mesmo no ato sexual, de uma visão do casal como coletivo, em proveito de uma representação mais individual do prazer.

Nota-se, finalmente, entre 1970 e a década de 90, uma grande mudança, entre as mulheres, nas normas relativas à fidelidade e às relações extraconjugais, enquanto as opiniões dos homens variam muito pouco. Em 1970, a maioria das mulheres declarava que a infidelidade de um homem casado era uma coisa perdoável. Em 1992, a tolerância tradicional está desgastada, e a maioria das mulheres já não acha aceitáveis as aventuras extraconjugais. Assim, em lugar de se traduzir numa tolerância maior em relação aos homens, a crescente autonomia das mulheres no casal se manifesta, ao contrário, numa exigência maior em relação ao parceiro, na medida em que ficou mais fácil interromper uma relação não satisfatória.

Essa evolução inesperada não pode ser interpretada como uma volta atrás de cunho conservador, pois outros índices mostram uma crescente abertura. No mesmo período, por 
Sexualidade e conjugalidade

exemplo, a proporção de homens e de mulheres que consideram que "os homossexuais são pessoas como as outras" passa de um terço a dois terços dos entrevistados..$^{15}$ Tornou-se ilegítimo atacar ou condenar abertamente comportamentos que até recentemente eram clandestinos ou escandalosos.

Desse breve panorama das mudanças recentes nos comportamentos podemos reter que a evolução é mais lenta do que em geral se acredita. As mulheres viveram mudanças mais marcantes que os homens. Ainda que as trajetórias sexuais dos homens e das mulheres se tenham aproximado, falta examinar como o confronto de uns e de outras se opera nas diversas etapas do intercâmbio sexual, notadamente na iniciação sexual e amorosa, e no curso da vida conjugal.

\section{Investimentos divergentes na iniciação amorosa}

Por corresponder à entrada na sexualidade com parceiro, a iniciação sexual e amorosa é um dos momentos decisivos na construção e na interiorização das relações entre os sexos. Desde a adolescência ou o fim da adolescência, manifestam-se importantes diferenças de atitudes entre os rapazes e as moças em termos de sexualidade, assim como entre os próprios rapazes, enquanto que as atitudes e comportamentos femininos são mais homogêneos, pelo menos nessa idade. ${ }^{16}$ Isso aparece claramente no exame do desenrolar da primeira relação sexual (que pode ser tomada como um indicador) e da maneira como se organiza a relação com o primeiro (a primeira) parceiro(a) sexual e com aqueles(as) que o(a) sucedem. Entre as razões que os(as) levaram a ter uma relação

\footnotetext{
${ }^{15}$ LHOMOND, B. e MiCHAELS, S. Homosexualité/hétérosexualité: les enquêtes sur les comportements sexuels en France et aux USA. Journal des Anthropologues, n’s 82-83, 2000, pp.91-110.

${ }^{16}$ Bozon, M. L'entrée dans la sexualité adulte... Op. cit.; Bozon, M. e HEILBORN, M.L. As carícias e as palavras. Iniciação sexual no Rio de Janeiro e em Paris. Novos Estudos, n 59, março de 2001, p.111-135; LAGRANGE, H. e LHOMOND, B. L'entrée dans la sexualité... Op. cit.
} 
com a(o) primeira(o) parceira(o) sexual, os adolescentes de 15 a 18 anos declaram com maior freqüência o desejo, a atração ou a curiosidade, enquanto as moças indicam em geral o amor ou o carinho: $59 \%$ dos meninos contra $34 \%$ das meninas mencionam o primeiro conjunto de motivos, e $38 \%$ contra $61 \%$, respectivamente, o segundo. ${ }^{17}$ Entre os rapazes, a tendência a declarar ter experimentado sentimentos amorosos pela primeira parceira é particularmente fraca no grupo que se iniciou sexualmente cedo (por exemplo, ao 15 ou 16 anos). Ao contrário, é alta entre aqueles de iniciação mais tardia (19 ou 20 anos). Por sua vez, as moças, a qualquer idade que se iniciem sexualmente, declaram muito amor pelo primeiro parceiro. ${ }^{18}$ Mais que um sentimento, o amor é aqui uma fórmula, um código de regulação das relações ${ }^{19}$ : só se fala de amor em relações que responderam a uma aspiração, que se fizeram esperar e que duraram (duram).

Essa grande diferença nas expectativas em relação à sexualidade e ao casal é ao mesmo tempo causa e conseqüência do fato de que os relacionamentos se estabelecem entre parceiros de idades diferentes. Sabe-se que os casais (casados e cohabitantes) se caracterizam em geral por uma diferença etária em favor do homem, que não se reduziu nas décadas recentes. ${ }^{20}$ Mas essa diferença existe já entre os parceiros desde os primeiros passos na sexualidade, o que tem conseqüências importantes para o mercado dos encontros sexuais adolescentes. Os autores da pesquisa sobre a sexualidade dos jovens descrevem assim a situação dos adolescentes:

As adolescentes de 15 a 18 anos recrutam seus parceiros essencialmente... entre os rapazes de 15 a 21 anos,

\footnotetext{
${ }^{17}$ LagRAnge, H. et LhOmond, B. L'entrée dans la sexualité... Op. cit., p.176.

${ }^{18}$ BozON, M. L'entrée dans la sexualité adulte... Op. cit.

${ }^{19}$ LUHMANN, N. L'amour comme passion. Op. cit.

${ }^{20}$ Bozon, M. Les femmes et l'écart d'âge entre conjoints. Une domination consentie I et II. Population, 2, pp.327-360 et Population, 3, pp.565-602, 1990.
} 
Sexualidade e conjugalidade

enquanto que as parceiras dos adolescentes de 15 a 18 anos pertencem ao mesmo grupo de idade que eles. ${ }^{21}$

Entre 15 e 18 anos há no total uma mulher para dois homens. Desde a adolescência, há uma vontade, de uma parte das meninas, de relacionar-se com homens ou rapazes mais velhos, considerados mais "interessantes" ou mais maduros, enquanto que os da mesma idade são considerados socialmente "jovens". Com dificuldade de encontrar meninas que os "queiram bem", os adolescentes não podem se fazer de difíceis. Beneficiadas por um excesso de parceiros potenciais, as moças, por sua vez, devem estabelecer princípios de escolha "que, no essencial, tomam a forma de uma seleção pelo sentimento amoroso". ${ }^{22} \mathrm{O}$ amor, pois, é também um procedimento de triagem, não forçosamente consciente, mais ou menos necessário segundo a abundância ou carência de parceiros potenciais.

Aqueles e aquelas que, desde a adolescência, associam sistematicamente a sexualidade ao amor ou ao casal não fazem mais que tentar discipliná-la, inscrevendo-a numa duração e num quadro que a ultrapassam. Num contexto, a França, onde o casamento deixou de ser um horizonte próximo e universal da sexualidade juvenil e onde o cônjuge não é mais o primeiro parceiro, dois modelos de organização dos primeiros anos da vida sexual se distinguem claramente. Num caso, os primeiros anos da vida sexual são ocupados por relacionamentos amorosos prolongados, a solidão é rara, e o primeiro relacionamento é com freqüência mais longo que a segundo. Um segundo modelo de iniciação da vida sexual passa ao contrário por relacionamentos breves, imediatamente sexualizados, com grande número de parceiros e longos intervalos sem atividade sexual. ${ }^{23} \mathrm{O}$ primeiro

${ }^{21}$ Lagrange, H. e LhOMOND, B. L'entrée dans la sexualité... Op. cit., p.182.

${ }^{22}$ ID., IB., p. 178

${ }^{23}$ LEVINSON, S. L'organisation temporelle des premières relations sexuelles. In: LAGRANGE, H. e LHOMOND, B. L'entrée dans la sexualité... Op. cit., pp.227-254. 
Michel Bozon

modelo é mais freqüente entre as mulheres, o segundo, entre os homens. Os primeiros anos da vida sexual oferecem às mulheres uma experiência relacional maior que aos homens, que terão tido experiências sexuais pontuais, ainda que alguns deles (aqueles de iniciação mais tardia) tenham de repente atitudes $e$ comportamentos próximos aos das moças. Em geral, os rapazes alcançam uma experiência relacional apenas no final de alguns anos de sexualidade de experimentação. Para eles, desde o início de sua vida sexual adulta, a sexualidade é uma maneira de ganhar segurança e confiança em si mesmos, enquanto que para boa parte das mulheres ela é simplesmente parte integrante de relacionamentos que elas querem duradouros.

A passagem para uma vida conjugal adulta não implica nos mesmos ajustamentos para uns e outras no decorrer da juventude. Para os rapazes ela implica na renúncia a aquela visão "experimental" de uma vida sem compromissos, um amadurecimento ("é preciso comportar-se"), enquanto que as meninas passam com freqüência por uma fase de desencanto amoroso depois da primeira separação juvenil, o que lhes permite adquirir uma postura mais individualista e aceitar uma visão mais realista e menos idealizada do "homem de sua vida". ${ }^{24}$

\section{Curso da vida sexual e relações entre homens e mulheres}

Mais de quatro quintos dos indivíduos, depois de um período mais ou menos longo de vida solitária ou de relações que não se consolidam, estabelece um relacionamento conjugal mais ou menos duradouro. A sexualidade do casal segue fases que se organizam num curso regular, ligado essencialmente à duração da vida comum, mas também ao calendário (eventual) do nascimento de filhos: à fase do casal nascente, relativamente

${ }^{24}$ Bozon, M. Désenchantement et assagissement: les deux voies de la maturation amoureuse. Le Journal des Psychologues, 159, 1998, pp.45-51. 
Sexualidade e conjugalidade

uniforme, segue-se a fase do casal estável, com formas mais diversas (segundo, por exemplo, o lugar que os filhos ocupam) e provavelmente uma terceira fase, ainda pouco conhecida, aquela do casal dessexualizado. ${ }^{25}$

\section{As fases da vida sexual conjugal}

O casal nascente corresponde aos primeiros dois ou três anos da vida comum. Distingue-se claramente por uma freqüência elevada de atividade sexual (três ou quatro relações por semana), por uma grande importância atribuída à exclusividade sexual (ou fidelidade) e por um nível relativamente elevado de disfunções sexuais (ejaculação precoce, falta de orgasmo), o que não impede os parceiros de estarem particularmente satisfeitos com sua vida sexual. Ainda sobre outros pontos aparece grande acordo entre os cônjuges: declaram-se ambos muito apaixonados (contrariamente ao que se observou na iniciação sexual), e a iniciativa das relações sexuais é muito mais compartilhada do que nas fases posteriores do casal. A atividade sexual inicial da vida conjugal é marcada ao mesmo tempo pela inexperiência dos parceiros e por uma grande reciprocidade em suas tentativas. A sexualidade nascente é inteiramente dedicada à construção do casal. É sobre a relação sexual que recai o peso de criar a díade conjugal.

Quando o casal se estabiliza, depois de alguns anos, começa uma nova fase de atividade sexual. Há uma diminuição no ritmo das relações (cerca de 2 por semana). Um ritual sexual que muda muito pouco entra em funcionamento, o nível das disfunções diminui, ao mesmo tempo (e paradoxalmente) que a satisfação

${ }^{25}$ UenO, C. Désexualisation de la famille: au-delà de la modernité sexuelle. In: ÉPHÉSIA. La place des femmes. Les enjeux de l'identité et de l'égalité au regard des sciences sociales. Paris, La Découverte, 1995, pp.100-110; DuncomBE, J. e MARSDEN, D. Whose orgasm is this anyway? "Sex Work" in long-term heterosexual couple relationships. In: WEEKS, Holland. (eds.) Sexual cultures. Communities, values and intimacy. London, Mac Millan, 1996, pp.220-238; Bozon, M. Amour, désir, durée. Op. cit. 
Michel Bozon

dos parceiros em relação à sua vida sexual cai bastante. A atividade sexual se torna um ritual privado, habitual $e$ consolidado, que confirma, mantém e materializa o laço. Não pode impedir que os sentimentos amorosos dos cônjuges se tornem menos vivos, em particular os das mulheres, e que o valor atribuído à fidelidade diminua. Nalgum momento, alguns cônjuges tem relações extraconjugais.

\section{A divergência dos desejos}

Uma das características do casal estabilizado, por contraste com o casal nascente, é que os investimentos femininos $e$ masculinos na sexualidade tendem a divergir, $e$ isso de maneira crescente no tempo. $\mathrm{Na}$ pesquisa sobre os comportamentos sexuais em 1992, foi feita uma pergunta sobre a última relação ${ }^{26}$ : "Para você, naquele momento, quem tinha mais vontade dessa relação sexual? Você. Vosso(a) parceiro(a). Os dois igualmente. Nenhum dos dois". Poucos homens e mulheres casados dizem que o desejo feminino prevalece. As mulheres, mais que os homens, declaram que o desejo masculino era dominante, ao passo que os homens são mais numerosos que as mulheres ao dizer que a vontade de ter a relação era igualmente compartilhada. À medida que aumenta a duração da vida conjugal, as declarações de desejo feminino e de desejo compartilhado declinam, e aumentam, sobretudo, as "divergências" entre homens e mulheres. Ao passo que as respostas eram bastante similares entre os casais que ainda não tinham filhos, uma forte distinção nas percepções que os homens $e$ as mulheres tem de suas relações sexuais aparece nos casais que tem filhos pequenos: as mulheres acham que as relações nesse momento se devem, sobretudo, ao desejo que o homem tem, e os homens freqüentemente continuam a vê-las como uma atividade igualmente desejada por um e por outro. As coisas se passam

${ }^{26}$ Bozon, M. Amour, désir, durée. Op. cit. 
Sexualidade e conjugalidade

como se as mulheres achassem que seu desejo pessoal $e$ sua participação ativa fossem menos indispensáveis à vida sexual do casal, a atividade sexual sendo considerada como um mecanismo que funciona mesmo na ausência do desejo. Depois do nascimento dos filhos, os homens, por seu lado, declaram com mais ênfase do que suas parceiras que o desejo é compartilhado. Isso não indica, necessariamente, uma atitude conjugal deles. Levantamos a hipótese de que para eles as relações sexuais funcionam como um ritual de confirmação do indivíduo (mais do que do casal), no qual este espera que o desejo de sua parceira responda ao seu, numa ótica narcisista. Podemos falar aqui de um modelo de desejo individualista. Assim, mesmo nos casais estáveis, que fundam uma família, as divergências em relação à sexualidade, que podem se traduzir concretamente por um desacordo em relação à freqüência das relações desejadas, são um fato corriqueiro. Elas aparecem, ou re-aparecem, sobretudo nos momento de procriação. É ilusório acreditar que o fato de viver junto conduza os cônjuges a criar um universo comum de sexualidade.

O desejo masculino e o desejo feminino não são simétricos num casal. Nas representações corriqueiras, uma mulher pode dizer que não tem desejo, sem que sua identidade social sofra por isso, especialmente depois que ela se tornou mãe. Mas a identidade do homem é potencialmente ameaçada em caso de ausência do desejo. Existe uma espécie de consenso em considerar que o desejo masculino tem mais direito a se expressar, ou mais legitimidade, do que o desejo feminino. Passada a iniciação do casal, a sexualidade tornar-se-ia um âmbito masculino, no qual o papel da mulher seria de responder à solicitação do homem, antes que de propô-la. A ausência de iniciativas das mulheres na vida sexual conjugal reproduz, no plano da intimidade, uma atitude observada nas primeiras etapas da formação do casal: evitar tomar oficialmente a iniciativa de aproximação no encontro amoroso, não dominar o cônjuge, nem 
pela idade, nem pelo tamanho. ${ }^{27}$ Esta atitude de espera não é necessariamente uma passividade: deixando-se desejar, elas podem adquirir uma influência indireta sobre aquele que deseja, $e$ ter a impressão de controlar o jogo amoroso ou conjugal. Outro fator interfere nesse apagamento progressivo do desejo feminino: a rivalidade entre o papel conjugal e o papel parental, que é mais exacerbada para as mulheres e que faz declinar o lugar relativo da sexualidade na relação entre cônjuges e na representação que elas tem de sua identidade.

\section{Desejo compartilhado e igualitarismo conjugal}

Ainda que o "igualitarismo sexual" não seja dominante nos casais que permanecem unidos, uma minoria de mulheres e de homens declara, depois de vários anos de vida em comum, que, na última relação sexual, o desejo era compartilhado, ou igual. Esse reconhecimento de um desejo mútuo não está particularmente ligado a um nível social ou cultural elevado que correspondesse a uma atitude de "liberalismo cultural"; ele se inscreve, antes, num modo de organização do casal que podemos abordar tratando da divisão das tarefas. Numa relação conjugal na qual prevalece uma divisão estrita do trabalho entre os sexos (em detrimento das mulheres), o desejo das mulheres e o desejo mútuo são raramente expressos. Por outro lado, tudo o que caminha na direção de uma igualdade ou de uma cooperação entre homens e mulheres, seja ao nível das tarefas, seja ao das decisões, favorece o reconhecimento de um desejo compartilhado, isto é, feminino, que se torna mais "declarável": compartilhar as tarefas e o desejo mútuo vão juntos. De maneira geral, a procriação aparece como um dos momentos da história do casal no qual as relações de gênero, depois de uma fase inicial mais

${ }^{27}$ Bozon, M. Les femmes et l'écart d'âge entre conjoints... Op. cit.; Apparence physique et choix du conjoint. In: ROUSSEL, L. et HiBERT, T. La nuptialité en France et dans les pays développés. Paris, INED-PUF, Collection Congrès et Colloques, 1991, pp.91-110. 
Sexualidade e conjugalidade

indiferenciada ${ }^{28}$, se inclinam para uma diferenciação geradora de desigualdade. É o que acontece tanto com a divisão do trabalho doméstico, que se torna fortemente especializada e desigual depois do nascimento das crianças ${ }^{29}$, como também com a atividade sexual do casal.

\section{Rupturas conjugais e comportamentos sexuais}

Nas gerações recentes, a experiência da ruptura conjugal, seja após o casamento, seja após a coabitação, tornou-se banal, atingindo quase um casal em cada dois. À maioria das separações segue-se a formação de um segundo casal. Os períodos que se seguem a uma ruptura são propícios a um questionamento das atitudes anteriores em relação à sexualidade, sobretudo entre as mulheres. ${ }^{30}$ Algumas mulheres que se separam e que tem filhos mantêm relações amorosas estáveis sem formar um segundo casal (pelo menos não em seguida). Esta situação pode ser interpretada como conseqüência de uma dominação dos homens no mercado matrimonial, o que favorece as mulheres mais jovens e atrasa (mais do que impede) a formação de um segundo casal para as mulheres que tem um passado conjugal. Outra interpretação seria que essas mulheres dão prioridade a seus compromissos familiares. ${ }^{31}$ Podemos descrevê-la também, de maneira positiva, como sendo o fato de que essas mulheres, sem renunciar a uma vida sexual, se distanciam da orientação conjugal, em benefício de uma abordagem mais individualista: deixando de conceber a atividade sexual como parte de um casal, elas podem viver, num

${ }^{28}$ KAUfMANN, J.C. Sociologie du couple. Op. cit.

${ }^{29}$ Como nas pesquisas Emploi du temps, ver Brousse, C. La répartition du travail... Op. cit.

${ }^{30}$ Bozon, M. Amor, sexualidade e relações sociais de sexo na França contemporânea. Estudos Feministas (1), 1995, pp.123-135.

${ }^{31}$ VillenEUVE-GOKALP, C. Après la séparation: conséquences de la rupture et avenir conjugal. In: LeRIDON, $\mathrm{H}$. et VILLENEUVE-GOKALP, C. Constance et inconstances de la familla. Paris, INED-PUF, 1999, pp.137-164. 
contexto bem diferente do da adolescência, "experiências" sexuais que percebem como uma liberação. Quanto aos homens $e$ mulheres que formam um segundo casal, depois de uma vida conjugal de certa duração, eles tem de saída uma atitude bem menos "conjugal" em relação à sexualidade, suas atitudes no que diz respeito à fidelidade no casal, por exemplo, sendo muito menos estritas do que nos casais nascentes. ${ }^{32}$

\section{Duas representações da sexualidade}

Ainda que as trajetórias sexuais e afetivas dos homens e das mulheres se tenham aproximado bastante nas últimas décadas, as pesquisas sobre os comportamentos sexuais realizadas nos anos 1990 mostram diferenças sistemáticas nas respostas, que traduzem, de um lado, diferenças de comportamento, mas, sobretudo, interpretações ou modos de envolvimento com a sexualidade divergentes.

Em relação à moral sexual, dois pontos de vista substantivamente diferentes se opõem. Dois terços dos homens estão de acordo com a idéia segundo a qual "pode-se ter relações sexuais com alguém sem ser apaixonado", ao passo que dois terços das mulheres desaprovam esta idéia. Os homens são também mais numerosos em pensar que "pode-se ter aventuras sexuais durante o casamento", do mesmo modo que "a atração sexual leva forçosamente a transar com alguém" e que "pode haver amor sem fidelidade", ou que "as infidelidades passageiras reforçam o amor." As mulheres, ao contrário, muito mais que os homens, se mostram chocadas com as "trocas de parceiros", tanto quanto com a pornografia, ainda que homens e mulheres concordem, três quartos deles, em que as relações entre pessoas do mesmo sexo são aceitáveis.

$\mathrm{Na}$ pesquisa realizada em 1992, foram feitas perguntas a respeito do que as pessoas consideram como normal ou aceitável

${ }^{32}$ Bozon, M. Amour, désir, durée. Op. cit., p.198. 
Sexualidade e conjugalidade

numa relação sexual. Um pouco mais do que os homens, as mulheres consideraram a penetração como um elemento indispensável da relação sexual (65\% contra 59\%). E, como indicamos acima, as mulheres dão menos importância do que os homens à norma do orgasmo simultâneo. Algumas feministas defenderam a idéia de que a penetração vaginal correspondia a uma demanda masculina, a qual as mulheres se submetiam sem aderir a ela. ${ }^{33} \mathrm{Na}$ realidade, observa-se uma forte adesão das mulheres à penetração, o que não é fácil de interpretar. A perda de popularidade do orgasmo simultâneo indica o declínio de uma representação fusional das relações sexuais e da sexualidade em geral. O valor da penetração deve-se, provavelmente, ao fato de que ela é a manifestação mais concreta do laço e da aproximação dos parceiros na ocasião do encontro. A importância concedida à penetração contrasta com a reticência das mulheres em relação à masturbação, menos praticada por elas que pelos homens $e$ também sub-declarada. ${ }^{34}$ Ao passo que os homens não têm dificuldade em reconhecer que se masturbam, para a maioria das mulheres, reconhecer uma prática sexual solitária, que não pode encontrar lugar na história de um relacionamento, seria equivalente a "perder a cara".

Questionados sobre o número de parceiros com os quais tiveram relações sexuais durante sua vida, os homens $e$ as mulheres divergem fortemente; vimos que os números declarados pelos homens são bem superiores, e isto em todos os países. Levar em conta a prostituição feminina não basta para superar essa distância. O mais provável é que mulheres e homens, apesar da definição que lhe foi proposta, não atribuíram o mesmo sentido à palavra de parceiro. Umas computaram os homens com os quais tinham tido relacionamentos com uma certa duração, ao passo

${ }^{33}$ Dworkin, A. Intercourse. New York, The Free Press.1987; GIAMI, A. Cent ans d'hétérosexualité. Actes de la Recherche en Sciences Sociales, 128, 1999, pp.38-45.

${ }^{34}$ BÉJIN, A. La masturbation féminine. Un exemple d'estimation et d'analyse de la sous-déclaration d'une pratique. Population, 5, 1993, pp.1437-1450. 
que outras nomearam todos aqueles com os quais tiveram relações sexuais, por mais breves que fossem. As mulheres preferem não mencionar as experiências que não "contaram", que não correspondiam a sua idéia sobre o que deve ser um relacionamento. Elas interiorizam, assim, as expectativas sociais limitadoras a seu respeito, antecipando os julgamentos severos que são feitos sobre aquelas que tem experiências múltiplas. Essas limitações não pesam sobre os homens.

À pergunta sobre o número de pessoas pelas quais eles tinham se apaixonado durante sua vida, homens e mulheres declararam o mesmo número (3 ou 4), próximo ao total de parceiros sexuais declarados pelas mulheres. $\mathrm{O}$ relacionamento afetivo ou conjugal parece assim ser o quadro normativo da relação sexual para as mulheres.

Foi perguntado às pessoas entrevistadas se elas falavam de sua vida sexual e amorosa com outras pessoas. Muito mais do que os homens, as mulheres tratam do tema com confidentes, freqüentemente confidentes femininas. A confidência amorosa $e$ sexual entre mulheres não parece situar-se no registro do relato técnico da experiência sexual, mas antes no da história dos relacionamentos, da evolução dos sentimentos e dos problemas com os parceiros, dos quais a sexualidade é um indicador. Se o tema é objeto de conversas mais freqüentes entre as mulheres, parece ser porque a conjunção da atividade sexual, do laço afetivo e da relação conjugal tornou-se problemática, especialmente num contexto de autonomia pessoal crescente das mulheres.

As mudanças observadas ao longo dessas últimas décadas nas trajetórias, nas aspirações e nos comportamentos sexuais traduzem uma aproximação das experiências de homens $e$ mulheres, o que é exemplificado pela ampliação da etapa da sexualidade juvenil entre as mulheres. Essa aproximação só torna mais patente a existência de uma assimetria de gênero nos usos da sexualidade, que recebe novas justificativas. 
Sexualidade e conjugalidade

\section{Revolução sexual ou psicologização das relações de gênero?}

A interpretação da assimetria de gênero e das mudanças nas relações sexuais não pode ser feita sem um exame prévio da maneira pela qual as representações sociais dominantes vêm dando conta das evoluções recentes. Dois discursos, contraditórios e cúmplices, coexistem no que diz respeito às mudanças sexuais. De um lado, a sexualidade contemporânea é denunciada porque ela ocasionaria o nomadismo sexual dos indivíduos, a tirania do prazer e do desejo ${ }^{35}$, a permissividade e a promiscuidade. A autoafirmação das mulheres, que não saberiam mais ficar no seu lugar e não mais respeitariam os papéis naturais dos homens, levariam à sua "desvirilização". Esse discurso conservador, que se baseia na sexualidade para condenar radicalmente a perda contemporânea de valores, é especialmente freqüente nos países anglo-saxões, nos quais a defesa da moral sexual e dos valores tradicionais da família serve de bandeira política e religiosa: o simples uso dos termos permissiveness e promiscuity, sem boa tradução no francês, ilustra a reprovação em relação às mudanças que outros saúdam em nome da "revolução sexual". ${ }^{36}$ Lendo as coisas da perspectiva oposta, pode-se ter uma leitura positiva das transformações contemporâneas e ver nelas uma revolução sexual que enfim consagraria o direito ao prazer, a liberação das minorias sexuais e a igualdade sexual entre mulheres e homens, no quadro de um acesso generalizado à contracepção; de acordo com esta interpretação, de certo modo "messiânica", é, ao contrário, o período precedente que deve ser considerado como uma era de repressão, de hipocrisia e de tabu. Aqueles que sustentam tal interpretação estão prontos a qualificar como revolucionária qualquer novidade como o viagra, as trocas de parceiros ou o

${ }^{35}$ Guillebaud, J.L. La tyrannie du plaisir. Paris, PUF.1998.

${ }^{36}$ WeEKS, J. Sexuality and its discontents: Meanings, Myths and Modern Sexualities. London, Routledge, 1985. 
Michel Bozon

sexo virtual, ou a considerar a epidemia de AIDS como devastadora para a "liberdade sexual". A leitura conservadora e a leitura messiânica se referem, de fato, menos a dados verificáveis e mais a julgamentos de valores opostos, inscritos em orientações de referência que definem estreitamente o olhar sobre a sexualidade. Mas as clivagens contemporâneas não se situam obrigatoriamente onde as colocam as duas interpretações rivais.

Se a sexualidade se tornou a linguagem básica do relacionamento (e não mais seu sub-produto), isso não se traduz numa revolução nas relações de gênero que teria modificado radicalmente os lugares de cada um. A auto-elaboração dos atores produz um sistema de gênero tão rígido como as injunções $e$ controles sociais antigos. Mostramos que as experiências sexuais dos indivíduos no mundo contemporâneo continuam a ser estruturadas por pares de oposição em tensão permanente. À busca pela continuidade na relação entre dois parceiros, opõe-se a exigência da espontaneidade do desejo. À busca pela reciprocidade, opõe-se a do prazer individual. À exigência de exclusividade, opõe-se a atração por uma possível simultaneidade de laços sexuais. Ao ideal de um parceiro para toda a vida, opõese a aspiração a uma renovação das experiências e dos relacionamentos. Ora, essas oposições tendem a fixar-se numa divisão de trabalho estável entre os sexos, geralmente justificada em termos de diferenças de natureza psicológica entre homens e mulheres.

Enquanto os homens são vistos como sujeitos desejantes independentes, a mulheres continuam a ser vistas como objetos a serem possuídos. Assim, nas formas modernas de trocas de parceiros, que se apóiam fundamentalmente no casal ${ }^{37}$, o homem tem acesso a outras mulheres, oferecendo a sua, freqüentemente reticente, a outros homens. A permanência de uma violência sexual arcaica contra as mulheres indica que a dominação

${ }^{37}$ WeLZER-LANG, D. L'échangisme: une multisexualité commerciale à forte domination masculine. Sociétés Contemporaines, n 41-42, 2001, p.111-131. 
Sexualidade e conjugalidade

masculina pode sempre tomar formas extremas; ela ocorre mais freqüentemente no âmbito privado dos casais do que no espaço público, mas ela é aí mais dificilmente reconhecida ${ }^{38}$, como se fosse vergonhoso para as mulheres que a sexualidade conjugal não exprima coesão. De fato, cabe sempre às mulheres resolver as tensões da sexualidade: sua atitude mais freqüente é a de tentar estabilizar e regular o desejo dos homens, contendo-o no interior de um relacionamento amoroso ou de um casal. Essa assimetria social entre os sexos leva a desprezar ou a desconfiar das mulheres que têm muitos parceiros (mulheres "fáceis") ou daquelas que não os têm (mulheres incompletas). O homem sexualmente experiente e o solteiro não passam por esta desvalorização. O valor das mulheres deriva de sua raridade ${ }^{39}$, o dos homens do número de "objetos" possuídos: a oposição raridadel número tornou-se uma estrutura psicológica profundamente interiorizada, como mostra a divergência nas respostas às questões a respeito do número de parceiros sexuais. Por fim, a sexologia contemporânea não se refere aos mesmos problemas quando trata de homens e mulheres: para os primeiros, o que é problemático é o desejo; para as segundas é o orgasmo, os homens continuando a ser considerados como os agentes principais do ato sexual. ${ }^{40} \mathrm{O}$ desejo sexual feminino continua a ser amplamente ignorado, "como se o jogo [das mulheres] devesse limitar-se à afetividade". ${ }^{41}$

\footnotetext{
38 JASPARD, M. et groupe ENVEFF. Nommer pour compter. Les violences à l'encontre des femmes en France. Population et sociétés, n³64, janvier 2001.

${ }^{39}$ THERY, I. Une "femme comme les autres". Séropositivité, sexualité et féminité. In: Séropositivité, vie sexuelle et risque de transmission du VIH. Paris, ANRS, 1999, p.113-136.

${ }^{40}$ Bozon, M. Les significations sociales des actes sexuels. Actes de la Recherche en Sciences Sociales, 128, 1999, pp.3-23.

${ }^{41}$ BAJOS, N. et BozON, M. La sexualité à l'épreuve de la médicalisation: le Viagra. Actes de la Recherche en Sciences Sociales, 128, 1999, pp.34-37.; ID., IB., p.34.
} 
Michel Bozon

\section{Conclusão}

A importância da subjetividade na construção do casal contemporâneo tem sido freqüentemente enfatizada. ${ }^{42}$

$\mathrm{Na}$ reflexão a respeito da desinstitucionalização do casamento e da vida familiar ${ }^{43}$, a conjugalidade contemporânea foi caracterizada como baseada no sentimento amoroso. Este substituiu a instituição do casamento que, ha pouco tempo ainda, era o fundamento do casal. A instabilidade crescente dos casais é atribuída à existência daquele fundamento afetivo tão incerto $e$ tão flutuante. Gerador de expectativas excessivas, o amor cria, de fato, desilusões muito fortes. A teoria, no entanto, negligencia o fato de que os casais podem se manter por muito tempo, mantendo um relacionamento bastante distanciado da paixão inicial.

De fato, o casal se constrói na duração. Ao "tempo da descoberta", sucede o do "conforto" ${ }^{44}$ Os hábitos e os objetos têm grande peso na consolidação, também chamada de objetivação, do casal. É ao criar um ambiente que amplia seu ego, povoado de objetos e do qual o casal faz parte, que os indivíduos constroem, a dois, um casal mais resistente. Passado o tempo da descoberta, a sexualidade entra plenamente nessas rotinas de construção e de manutenção de um ego conjugal.

A centralidade da sexualidade na existência do casal contemporâneo é incontestável. Esse ritual privado não pode faltar sem que todo o edifício conjugal seja posto em risco. ${ }^{45} \mathrm{~A}$ ambigüidade da sexualidade conjugal deriva de que ela é exercida

${ }^{42}$ Goode, W. World Revolution and Family Patterns. Glencoe, The Free Press, 1963; Berger, P. et Lellman, H. Le mariage et la construction sociale de la réalité. Dialogue, 102, 1988, pp.6-23 [primeira publicação, 1960]; RouSSEL, L. La famille incertaine. Paris, Odile Jacob, 1989; KAUFMANN, J.C. La trame conjugale. Analyse du couple par son linge. Paris, Nathan, 1992.

${ }^{43}$ RouSSEL, L. La famille incertaine. Op. cit.

${ }^{44}$ KaufmanN, J.C. La trame conjugale... Op. cit.

${ }^{45}$ Bozon, M. Amour, désir, durée. Op. cit. 
Sexualidade e conjugalidade

por homens e mulheres com interpretações distintas, cujos cenários são progressivamente construídos no curso da socialização, a partir de experiências biográficas socialmente estruturadas. Em muitos aspectos, o modo de funcionamento do casal nascente, marcado pelo forte envolvimento e convergência de estilo dos atores, é excepcional na história dos relacionamentos individuais. A sexualidade juvenil se caracteriza desde o início por diferenças muito grandes entre as preocupações dos rapazes e das moças. Depois, quando o casal se estabiliza, passada a fase dos começos, os interesses de cada um pela atividade sexual começam a divergir, com a tendência a uma especialização crescente nos papéis de gênero, reforçados com a duração e a parentalidade. Definitivamente, talvez seja nas trajetórias sexuais e afetivas que se seguem a uma ruptura conjugal e na atividade sexual nas idades mais avançadas que se observa, na época contemporânea, as maiores renovações na maneira pela qual as relações de gênero são sexualmente postas em cena, principalmente por causa das transformações das atitudes das mulheres. 